\title{
Food Safety and Invasive Cronobacter Infections during Early Infancy, 1961-2018
}

Jonathan Strysko, Jennifer R. Cope, Haley Martin, Cheryl Tarr, Kelley Hise, Sarah Collier, Anna Bowen

\section{$\underset{\text { MEUCATION }}{\text { Medsce ACTIVITY }}$}

In support of improving patient care, this activity has been planned and implemented by Medscape, LLC and Emerging Infectious Diseases. Medscape, LLC is jointly accredited by the Accreditation Council for Continuing Medical Education (ACCME), the Accreditation Council for Pharmacy Education (ACPE), and the American Nurses Credentialing Center (ANCC), to provide continuing education for the healthcare team.

Medscape, LLC designates this Journal-based CME activity for a maximum of 1.00 AMA PRA Category 1 Credit(s) ${ }^{\mathrm{TM}}$. Physicians should claim only the credit commensurate with the extent of their participation in the activity.

Successful completion of this CME activity, which includes participation in the evaluation component, enables the participant to earn up to $1.0 \mathrm{MOC}$ points in the American Board of Internal Medicine's (ABIM) Maintenance of Certification (MOC) program. Participants will earn $\mathrm{MOC}$ points equivalent to the amount of CME credits claimed for the activity. It is the CME activity provider's responsibility to submit participant completion information to ACCME for the purpose of granting ABIM MOC credit.

All other clinicians completing this activity will be issued a certificate of participation. To participate in this journal CME activity: (1) review the learning objectives and author disclosures; (2) study the education content; (3) take the post-test with a $75 \%$ minimum passing score and complete the evaluation at http://www.medscape.org/journal/eid; and (4) view/print certificate. For CME questions, see page 1057.

\section{Learning Objectives}

Release date: April 15, 2020; Expiration date: April 15, 2021

Upon completion of this activity, participants will be able to:

- Describe clinical characteristics and outcomes of Cronobacter bloodstream infection or meningitis among infants as reported to the CDC and in the literature from 1961 to 2018

- Determine epidemiological features of Cronobacter bloodstream infection or meningitis among infants as reported to the CDC and in the literature from 1961 to 2018

- Identify clinical and public health implications of epidemiology and outcomes of Cronobacter bloodstream infection or meningitis among infants as reported to the CDC and in the literature from 1961 to 2018.

\section{CME Editor}

Deborah Wenger, MBA, Copyeditor, Emerging Infectious Diseases. Disclosure: Deborah Wenger, MBA, has disclosed no relevant financial relationships.

\section{CME Author}

Laurie Barclay, MD, freelance writer and reviewer, Medscape, LLC. Disclosure: Laurie Barclay, MD, has disclosed no relevant financial relationships.

\section{Authors}

Disclosures: Jonathan Strysko, MD; Jennifer R. Cope, MD, MPH; Haley Martin, BS; Cheryl L. Tarr, PhD; Kelley B. Hise, MPH; Sarah Collier, MPH; and Anna Bowen, MD, MPH, have disclosed no relevant financial relationships.

Invasive Cronobacter infections among infants are associated with severe neurologic disabilities and death. Early Cronobacter reports typically featured hospitalized and preterm infants and recognized contaminated powdered infant formula (PIF) as a transmission vehicle. To clarify recent epidemiology, we reviewed all cases of bloodstream infection or meningitis among infants that were reported to the Centers for Disease Control and Prevention

Author affiliation: Centers for Disease Control and Prevention, Atlanta, Georgia, USA

DOI: https://doi.org/10.3201/eid2605.190858 and in the literature $(1961-2018 ; n=183)$. Most infants were neonates (100/150 [67\%]); 38\% (42/112) died, and $79 \%(81 / 102)$ had reported recent PIF consumption. In the final quarter of the study period (2004-2018), case counts were significantly higher (global average 8.7 cases/year); among US cases, significantly higher proportions occurred among full-term (56\% [27/48]) and nonhospitalized (78\% [42/54]) infants. PIF contamination, most commonly from opened containers, was identified in $30 \%(21 / 71)$ of investigations. Our findings reaffirm the need to promote safer alternatives for infant feeding, particularly among neonates. 
C ronobacter species are gram-negative bacteria known to cause severe and often life-threatening infections in infants. Invasive Cronobacter infections in infants, including bloodstream infections and meningitis (most commonly caused by C. sakazakii), can result in neurologic disability, as well as death; reported case-fatality rates are as high as $40 \%$ (1). Beginning in 1961, reports of invasive Cronobacter infections historically described predominantly hospitalized and preterm infants $(2,3)$. The identification of Cronobacter in association with several cases of necrotizing enterocolitis among infants reinforced its association with hospitalized infants born prematurely (4). However, previously healthy full-term infants are also known to become infected; infants born at more advanced gestational ages might be at greater risk than early preterm infants for having Cronobacter meningitis, as opposed to isolated bloodstream infection (1).

Because reporting is not mandatory in most countries (and in most of the United States), the true incidence of invasive infant Cronobacter infections is unknown. Estimates from laboratory-based surveillance in the United States suggest that $\approx 18$ infant cases of invasive Cronobacter infection (0.49 cases/100,000 infants) occur annually (5). In 2008, the World Health Organization $(\mathrm{WHO})$ reported the yearly incidence to be at least $0.14 / 100,000$ infants in the Philippines and 1.76/100,000 infants in England and Wales, although these are thought to be underestimates (6).

Cronobacter spp. can withstand desiccation in dried foods like powdered infant formula (PIF) and are known to thrive in reconstituted formula (7). Linked to outbreaks among hospitalized neonates in the 1980s, contaminated PIF has been identified as the transmission vehicle in nearly all Cronobacter infections for which a source was found $(3,8-10)$. The most recently identified US outbreak of Cronobacter infections linked to intrinsic contamination of a formula product (i.e., Cronobacter isolated from sealed formula containers) occurred in 2001 at a Tennessee hospital (11). That outbreak helped prompt the US Food and Drug Administration (FDA) in 2002 to discourage the use of PIF in neonatal intensive care settings unless there is no alternative available $(12,13)$. For hospitalized neonates, FDA recommended ready-to-feed (RTF) liquid formula, which is considered sterile until opened. WHO issued broader recommendations aimed at preventing Cronobacter transmission through hygienic PIF reconstitution and storage practices, emphasizing the importance of hand hygiene and advising that caregivers reconstitute PIF with water heated to $\geq 70^{\circ} \mathrm{C}$ (14). In 2014, FDA issued quality control standards aimed at safer
PIF production, including requiring manufacturers to routinely test for Salmonella and Cronobacter before distribution (15).

In 2016, the US Centers for Disease Control and Prevention (CDC) reported a case of invasive Cronobacter infection linked to contaminated expressed human breast milk (EBM) and the associated breast pump (16). After that case, 2 additional EBM-associated cases were reported in the literature, including 1 in a full-term neonate $(17,18)$. To characterize recent epidemiology in light of regulatory actions, enhanced surveillance and preventive efforts, and newly described modes of transmission, we analyzed all cases of invasive Cronobacter infection among infants that were reported to the CDC and documented in the literature.

\section{Methods}

We defined an invasive case as isolated bacteremia (Cronobacter isolated from blood) or meningitis (Cronobacter isolated from cerebrospinal or brain abscess fluid, with or without bacteremia) in an infant ( $<12$ months of age). We excluded cases of isolated Cronobacter urinary tract infection and Cronobacter-associated necrotizing enterocolitis from this analysis. We searched for invasive cases reported since the first published reports (1961-2018) (2). The Cronobacter genus was formerly known as the single species Enterobacter sakazakii. Therefore, we used the subject heading terms "Cronobacter" or "sakazakii" in combination with "newborn," "infant," or "neonate" to conduct a literature search of the Medline, Embase, CINAHL, Scopus, and Cochrane Libraries and review associated bibliographies. In addition, we included previously unpublished cases from CDC case consultations, cases reported in the 2008 Food and Agriculture Organization of the United Nations (FAO) and WHO meeting notes summarizing the international call for data on Cronobacter, and the PubMLST database, an internet-based repository of bacterial isolate genetic sequences $(6,19)$. PubMLST submission profiles occasionally report clinical and demographic information, which led to the identification of additional cases. We de-duplicated redundant cases reported in multiple data sources using information provided on patient age, location, and illness onset dates.

We used "community-onset cases" and "cases among non-hospitalized patients" interchangeably to signify that symptom onset occurred outside the hospital. We defined preterm birth as $<37$ weeks (early preterm, $<32$ weeks; late preterm, $\geq 32$ to $<37$ weeks) and full-term birth as $\geq 37$ weeks 
Food Safety and Cronobacter Infections

estimated gestational age (EGA). We defined a neonate as an infant $<28$ days of age. For PIF, we used any commercially manufactured PIF product, including powdered human milk fortifier. (In the United States, powdered formulas, including follow-on formulas, are classified as PIF if they are intended for use among infants).

In addition to reviewing clinical information and feeding histories for each case, we reviewed results of available case investigations. Although there was no standard definition for food consumption in relation to disease onset across data sources, CDC's reporting convention included any consumption within 7 days before symptom onset. Cronobacter infections are not nationally notifiable in the United States, but state and local health departments encountering new Cronobacter cases may contact CDC to request clinical consultation and submit clinical isolates, food, and environmental samples for laboratory testing. When possible, FDA tests PIF or other products from sealed containers of the same lots fed to the infant to assess whether contamination occurred during production. CDC used pulsed-field gel electrophoresis (PFGE) to assess similarity between clinical, food, and environmental isolates using 2 restriction enzymes, Xba1 and Spe1. However, PFGE might have limited capacity to differentiate between genetically unrelated strains within the same clonal complex. In other investigations, whole-genome sequencing and multilocus sequencing typing has offered more precise determinations of genetic similarity.

We considered cases to be outbreak-associated if the clinical isolate's PFGE pattern was indistinguishable from that of another case (invasive, noninvasive, or colonized). Alternatively, cases could be designated as outbreak-associated if they were detected in proximity with other cases both temporally (within 6 months) and spatially (in the same home or hospital). Defining the reporting period as 1961-2018, we compared reporting rates during the final quarter (20042018) with those during the preceding 3 quarters. We performed descriptive analysis using SAS software version 9.4 (https://www.sas.com), characterizing trends in annual reporting with negative-binomial regression, and comparing groups using $\chi^{2,} t$-tests, and Wilcoxon signed-rank tests.

\section{Results}

We identified 183 unique infants who met the case definition: 66 described in the literature, 61 from CDC case consultations, 53 from the WHO/FAO report, and 3 from PubMLST. Cases were reported from 24 countries across 6 continents (Table 1; Appendix
Table 1. Numbers of reported invasive Cronobacter infections among infants, by country, 1961-2018

\begin{tabular}{lcc}
\hline Country & $\begin{array}{c}\text { No. cases reported, } \\
\mathrm{n}=183\end{array}$ & Appendix reference* \\
\hline Argentina & 3 & $(16)$ \\
Australia & 1 & $(10)$ \\
Belgium & 2 & $(3,14)$ \\
Brazil & 8 & $(11,17-19)$ \\
Canada & 3 & $(20-22)$ \\
China & 3 & $(23,24)$ \\
Denmark & 1 & $(25)$ \\
France & 5 & $(4,15,26)$ \\
Germany & 1 & $(27)$ \\
Greece & 1 & $(28)$ \\
Iceland & 3 & $(6)$ \\
India & 2 & $(29)$ \\
Israel & 4 & $(12)$ \\
Japan & 2 & $(4,13)$ \\
Kenya & 1 & $(30)$ \\
Netherlands & 8 & $(2)$ \\
New Zealand & 1 & $(31)$ \\
Philippines & 16 & $(4)$ \\
Portugal & 1 & $(32)$ \\
Romania & 1 & $(33)$ \\
Spain & 1 & $(34)$ \\
Switzerland & 1 & $(35)$ \\
United Kingdom & 35 & $(1,4)$ \\
United States & 79 & $(5,7,8,9,36-48)$ \\
\hline${ }^{*}$ A full list of reviewed manuscripts is provided in the Appendix \\
(https://wwwnc.cdc.gov/EID/article/26/5/19-0858-App1.pdf). \\
\hline
\end{tabular}

(https://wwwnc.cdc.gov/EID/article/26/5/190858-App1.pdf). Global annual reporting was significantly higher during the final quarter of the study period, increasing from a mean of 1.2 cases/year before 2004 to 8.7 cases/year from 2004 on $(p<0.01)$. More than two thirds $(130 / 183)$ of the cases were reported in the final quarter, when the proportion of outbreakassociated cases was significantly lower both in the United States and internationally (Table 2).

Among 79 US cases, most (61 [77\%]) were reported to CDC; 15 cases were described in the literature only, most (13 [87\%]) published before 2004. The proportion of cases among nonhospitalized US infants increased significantly, from $44 \%(8 / 18)$ before 2004 to $78 \%(42 / 54)$ of cases for 2004-2018 ( $<<0.01$ by $x^{2}$ test) (Figure). The proportion of cases reported among full-term US infants was also higher during this period; $22 \%(4 / 18)$ before 2004, compared with $56 \%(27 / 48)$ for $2004-2018$ ( $\mathrm{p}=0.01$ by $\chi^{2}$ test) (Table 2). In contrast, outside the United States, a minority of cases occurred among nonhospitalized [15\% (7/47)] or full-term [31\% (11/47)] infants.

\section{Clinical Characteristics and Outcomes}

Overall, $116(63 \%)$ infants had meningitis and 67 (37\%) had isolated bacteremia. Compared with patients with isolated Cronobacter bacteremia, patients with Cronobacter meningitis were significantly more likely to have experienced onset outside the hospital 
Table 2. Characteristics of 183 infants with invasive Cronobacter infection, overall and by clinical syndrome type, geographic location, and reporting period, $1961-2018^{*}$

\begin{tabular}{|c|c|c|c|c|c|c|c|}
\hline \multirow[b]{2}{*}{ Characteristic* $^{*}$} & \multirow[b]{2}{*}{ Overall } & \multicolumn{2}{|c|}{ Syndrome type } & \multicolumn{2}{|c|}{ United States } & \multicolumn{2}{|c|}{ Outside United States } \\
\hline & & Bacteremia & Meningitis & $\begin{array}{l}\text { 1st-3rd } \\
\text { quarters, } \\
1961-2003\end{array}$ & $\begin{array}{l}\text { 4th quarter, } \\
2004-2018\end{array}$ & $\begin{array}{l}\text { 1st-3rd } \\
\text { quarters, } \\
1961-2003 \\
\end{array}$ & $\begin{array}{l}\text { 4th quarter, } \\
2004-2018\end{array}$ \\
\hline \multicolumn{8}{|l|}{ Sex } \\
\hline $\mathrm{F}$ & $50 / 103(49)$ & 20/35 (57) & $30 / 68(44)$ & $7 / 17(44)$ & $24 / 49(49)$ & 9/19 (53) & $9 / 18(50)$ \\
\hline M & $53 / 103(51)$ & $15 / 35(43)$ & $38 / 68(56)$ & $10 / 17(56)$ & $25 / 49(51)$ & $10 / 19(47)$ & $9 / 18(50)$ \\
\hline Cesarean delivery & $33 / 58(57)$ & $13 / 19(68)$ & $20 / 39(51)$ & $2 / 5(40)$ & $20 / 24(48)$ & $7 / 10(70)$ & $0 / 1(100)$ \\
\hline Died & $42 / 112(38)$ & $13 / 46(28)$ & 29/66 (44) & $4 / 21$ (19) & $9 / 42(21)$ & $14 / 27(52)$ & $14 / 21(67)$ \\
\hline Neonatal onset & $100 / 150(67)$ & $36 / 55(65)$ & $64 / 95$ (67) & $16 / 24(67)$ & $40 / 55(73)$ & $19 / 20(95)$ & $16 / 20(80)$ \\
\hline Median onset age, $\mathrm{d}$ & $13(7-28)$ & $17(9-33)$ & $11(6-22)$ & $20(10-35)$ & $16.5(11-30)$ & $5(4-14)$ & $11.5(5-60)$ \\
\hline Median EGA, wks & $36(31-40)$ & 31(27-39) & $36(32.2-39)$ & $32(30-36)$ & 37 (32.2-39) & $37(32-40)$ & 31 (27.7-40) \\
\hline Median birthweight, g & $\begin{array}{c}2,155 \\
(1,400- \\
2,948)\end{array}$ & $\begin{array}{c}1,626 \\
(1,044- \\
2,845)\end{array}$ & $\begin{array}{c}2,514 \\
(1,843- \\
2,989)\end{array}$ & $\begin{array}{c}1,475 \\
(900-2,477)\end{array}$ & $\begin{array}{c}2,594 \\
(1,815-3,118)\end{array}$ & $\begin{array}{c}2,277 \\
(1,545-2,775)\end{array}$ & $\begin{array}{c}1,570 \\
(1,269-1,980)\end{array}$ \\
\hline Community onset & $57 / 119(48)$ & $32 / 48(67)$ & $41 / 71(58)$ & $8 / 18(44)$ & $42 / 54(77)$ & $2 / 25(8)$ & $5 / 22(23)$ \\
\hline Full-term birth & $41 / 100(41)$ & $11 / 33(33)$ & $30 / 67$ (45) & $4 / 18(22)$ & $27 / 48(57)$ & $10 / 20(50)$ & $1 / 15(7)$ \\
\hline Late preterm birth & 29/100 (29) & $4 / 33(12)$ & $25 / 67$ (37) & $5 / 18(27)$ & $13 / 48(27)$ & $6 / 20(30)$ & $6 / 15(40)$ \\
\hline Early preterm birth & $30 / 100(30)$ & $18 / 33(55)$ & $12 / 66(18)$ & $9 / 18(50)$ & $9 / 48(19)$ & $4 / 20(20)$ & $8 / 15(53)$ \\
\hline Outbreak-associated & $33 / 125(26)$ & $11 / 47(23)$ & $22 / 78(28)$ & $4 / 21(19)$ & $2 / 53(4)$ & $20 / 29(69)$ & $7 / 22(32)$ \\
\hline \multicolumn{8}{|c|}{$\begin{array}{l}\text { *Values are no. (\%) or median (interquartile range). Neonatal onset defined as } \leq 28 \mathrm{~d} \text { after birth; full-term birth was } \geq 37 \text { weeks EGA; late preterm birth, } \\
32-37 \text { weeks EGA; early preterm birth, }<32 \text { weeks EGA. Outbreak-associated was defined as a clinical isolate's pulsed-field gel electrophoresis pattern } \\
\text { indistinguishable from that of another case (invasive, noninvasive, or colonized) or if detected in proximity with other cases both temporally (within } 6 \text { mo) } \\
\text { and spatially (in the same home or hospital). Bold type indicates statistical significance ( } p<0.05 \text { ) between reporting periods or syndrome types. EGA, } \\
\text { estimated gestational age. }\end{array}$} \\
\hline
\end{tabular}

(58\% [41/71] vs. 33\% [16/48]; p<0.01) and were typically born closer to term (median 36 weeks EGA vs. 31 weeks EGA; $p=0.01$ ) (Table 2). The median EGA of patients overall was 36 (IQR 31-40) weeks. Nearly all infants $(95 \%$ [140/148]) became ill within the first 2 months after birth, $67 \%(100 / 150)$ in the neonatal period; median age at symptom onset was 13 (IQR 7-28) days.

Immunocompromising conditions other than prematurity were reported in only 1 patient, a 10-monthold infant with severe combined immunodeficiency. Concurrent conditions (other than common prematurity-related complications) were also infrequently reported but included gastrointestinal anomalies ( $\mathrm{n}=$ $4[2 \%])$, congenital heart disease $(n=3[2 \%])$, and a neural tube defect $(n=1)$. Medical interventions before illness onset included enteral tube feeding $(n=16$ [9\%]), mechanical ventilation $(\mathrm{n}=10[5 \%])$, and recent antimicrobial drug therapy $(\mathrm{n}=9[5 \%])$.

Case-fatality overall was 38\% (42/112) and did not change significantly over time (Table 2). Among survivors, complications included cerebral abscess or infarction (27\% [18/67]) and hydrocephalus $(16 \%$ [11/67]).

\section{Feeding Practices and Case Investigations}

Feeding histories were described for 102 infants. Eighty-one (79\%) reported recent consumption of PIF, with or without other supplemental feeding types, and $48(47 \%)$ consumed PIF exclusively. Exclusive consumption of liquid infant formula was reported in
4 cases. Among 10 infants reported to consume only breastmilk in the 7 days before symptom onset, 5 received expressed breastmilk; reports did not clarify whether the breastmilk was expressed in the remaining 5 cases.

Source investigations were conducted for 71 $(39 \%)$ cases. At least one contaminated environmental or food isolate was identified for $31(44 \%)$ of these cases, and PIF contamination was identified in $30 \%(21 / 71)$ of investigations. Among 17 cases outside of the United States that had source investigations conducted, $14(82 \%)$ had a transmission vehicle identified; $11(79 \%)$ cases were linked to contaminated PIF (6 from sealed containers, 5 from opened containers), 2 (14\%) with blenders used to mix PIF, and $1(7 \%)$ with contaminated EBM/breast pump $(4,9,17,20-25)$.

Among 54 CDC-supported source investigations, $\geq 1$ contaminated environmental or food isolate was identified for 17 (32\%) investigations, each linked to a single case (Table 3 ). Cronobacter was isolated from $10(22 \%)$ of the 46 opened PIF containers tested; $5(50 \%)$ of these isolates were obtained during 2004-2018. CDC identified Cronobacter from opened PIF containers in 4 additional instances during 2004-2018; of these, 3 were associated with noninvasive cases and 1 was associated with a noninfant. All 4 PFGE patterns were indistinguishable from corresponding clinical isolates. FDA did not identify contaminated PIF from lot-matched sealed containers 
associated with clinical cases during 2001-2018; however, testing was not performed for all cases.

PIF preparation practices were recorded for only 4 cases in which Cronobacter was isolated from an opened PIF container. All caregivers reported proper hand hygiene; none reported reconstituting PIF using the WHO-recommended method of heating water to $\geq 70^{\circ} \mathrm{C}$. In addition, evidence of environmental contamination was found during investigations of 6 cases: sink surfaces $(n=4)$, a bottle nipple $(n=1)$, and a pacifier $(n=1)$. Two cases involved contaminated EBM/breast pumps, and 2 cases involved contaminated bottled water used to reconstitute PIF. Among Cronobacter isolates identified from contaminated food or environmental samples, PFGE patterns were indistinguishable from corresponding clinical isolates $81 \%(13 / 16)$ of the time.

\section{Discussion}

Our findings provide continued evidence that invasive Cronobacter infections disproportionately affect infants in the neonatal period and are associated with high mortality. Early Cronobacter reports often featured hospitalized and preterm infants, but our findings suggest a rising majority of cases occurring among nonhospitalized and full-term infants in the United States. Contaminated PIF from opened containers is the most commonly identified transmission vehicle.

Reports of invasive infant Cronobacter infections appear to have increased globally, despite the lack of mandatory reporting. It is unclear whether the true incidence increased; this reporting increase might be because of more precise microbiologic identification, increased interest following publicized outbreaks and the WHO call for cases, and greater awareness about the larger public health implications $(6,26)$. In addition, there was no name for Cronobacter spp. during the first quarter of reporting; early isolates were identified as Cronobacter spp. retrospectively. Enterobacter sakazakii was named as a species in 1980, and Cronobacter was proposed as a genus in 2007 (27). It is possible that the evolving nomenclature and identification methods may have resulted in both missed cases and inclusion of infections misclassified as Cronobacter.

Cronobacter reports outside the United States still predominantly feature hospitalized and preterm infants, whereas recent cases reported within the United States reflect higher proportions of cases among full-term, nonhospitalized infants. The reasons for these differences are likely multifactorial. Because we relied on published reports for cases among infants outside the United States, the characteristics of this group could have been influenced by a publishing bias; patients cared for in academic settings with advanced care capability might be the most likely to be detected and reported in the literature. In addition, outbreaks are more likely to be detected when cases occur in proximity, such as in neonatal intensive care units where most infants are preterm; although proportions of outbreak-associated cases declined globally in the final quarter, nearly one third of cases outside the United States were known to be associated with an outbreak (as opposed to $4 \%$ of US cases during that period). Likewise, the significant rise in cases among US full-term and nonhospitalized infants might be an

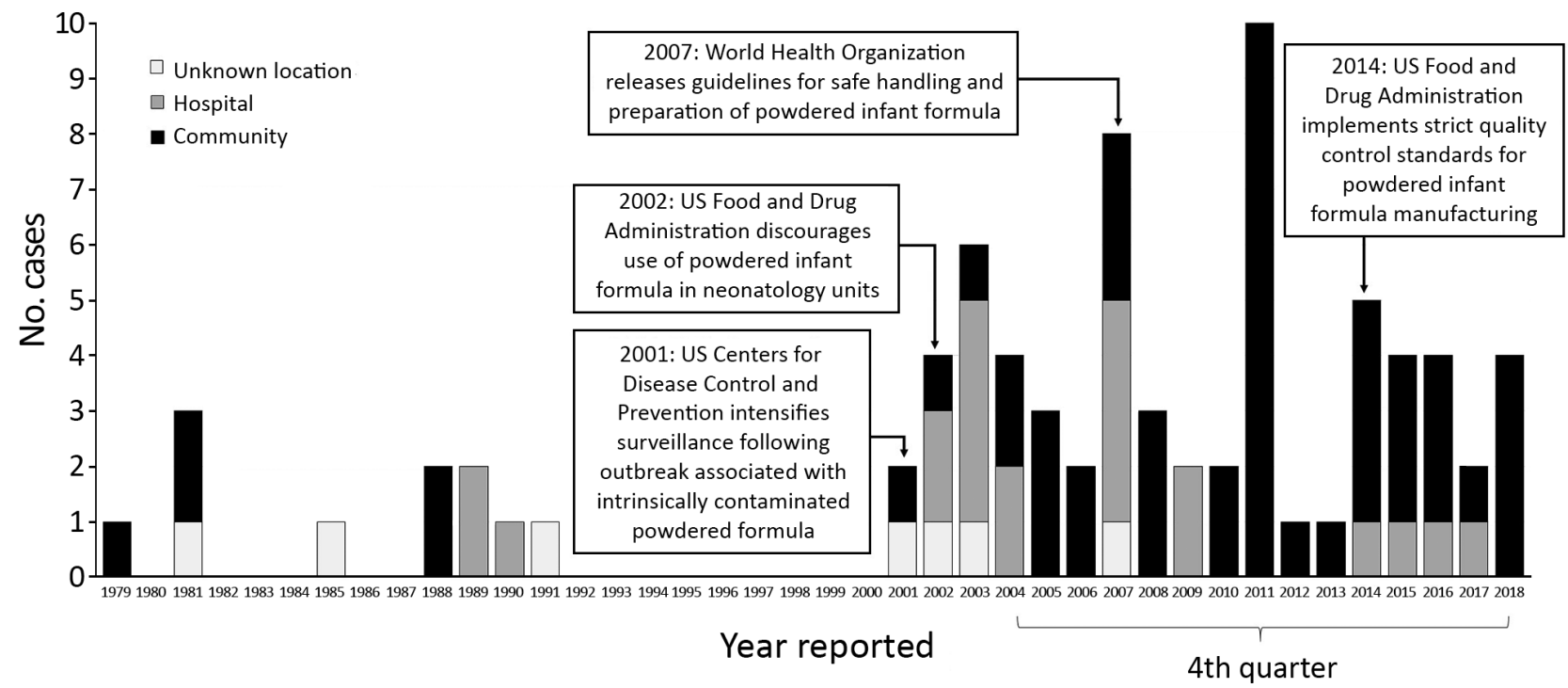

Figure. Reported invasive Cronobacter infections among infants, United States, 1979-2018, by location of patient at the time of symptom onset $(n=79)$. (The first case of invasive infant Cronobacter infection in the United States was reported in 1979 [13-15].) 
Table 3. Results of investigations supported by the Centers for Disease Control and Prevention for 54 cases of invasive Cronobacter infections among infants, United States, 1989-2018*

\begin{tabular}{|c|c|c|c|}
\hline Sample type & Sample type tested & $\begin{array}{c}\text { Sample yielded } \\
\text { Cronobacter }\end{array}$ & $\begin{array}{l}\text { Sample isolate } \\
\text { indistinguishable from } \\
\text { clinical isolate† }\end{array}$ \\
\hline PIF from opened containers & $46 / 52(87)$ & 10/46 (22)‡ & $6 / 7(86)$ \\
\hline Breast pump collection kit/pump-expressed breastmilk & $5 / 52(9)$ & $2 / 5(40)$ & $1 / 2(50)$ \\
\hline Water from opened bottle & $16 / 52(27)$ & 2/16 (13) & $1 / 1(100)$ \\
\hline Environmental surfaces & $17 / 52(31)$ & $6 / 17(35) \S$ & $4 / 6(67)$ \\
\hline \multicolumn{4}{|c|}{$\begin{array}{l}\text { *Values are no. positive/no. tested (\%). Results from first source investigation in the United States was reported in } 1989(8) \text {. } \\
\text { †Comparison made using pulsed-field gel electrophoresis. } \\
\text { †Cronobacter contamination was identified in powdered infant formula during investigations conducted during } 1989-2017 . \\
\text { §Of } 6 \text { cases that yielded an isolate from an environmental surface, } 4 \text { were from kitchen sink surfaces, } 1 \text { from a pacifier, and } 1 \text { from a bottle nipple. }\end{array}$} \\
\hline
\end{tabular}

artifact of surveillance changes during the period we examined; starting in 2001, CDC called for cases to be voluntarily reported in the United States, which likely contributed to higher proportions of sporadic cases being reported. Differential changes in risk exposure might also contribute to higher proportions of cases among full-term infants. In the United States, the 2002 FDA recommendation discouraging the use of PIF among hospitalized infants has likely helped prevent some cases among hospitalized and preterm infants; however, PIF continues to be used in neonatology units throughout much of the world (20).

High-risk groups for invasive Cronobacter infection include infants $<2$ months of age and infants born prematurely (even as reports of cases among full-term infants in the United States are becoming more common). Other clinical risk factors, however, are not straightforward. Immunocompromising and other concurrent conditions other than prematurity were not frequently reported and are not thought to be major drivers of disease acquisition in infants; reports of medical devices/interventions were also not common. Like previous reports, this analysis found Cronobacter meningitis was more common in full-term and late preterm infants, whereas Cronobacter bacteremia was more common in early preterm infants (1). The reason for this difference is unclear; however, timely initiation of empiric antimicrobial drug treatment among inpatients undergoing clinical monitoring could prevent invasion of bacteria beyond the blood-brain barrier (7).

PIF consumption was reported in most cases, and PIF from opened containers is the most commonly identified transmission vehicle. Even with small amounts of the remaining product available for testing, $10(22 \%)$ PIF containers yielded Cronobacter during US investigations. More than half of these Cronobacter-contaminated containers were identified during the final quarter of the analytic period, as recently as 2017. CDC also identified Cronobacter-contaminated PIF from opened containers being used to feed 4 additional noninfant children or infants with noninvasive infections during 2004-2018, which were not included in this analysis (CDC, unpub. data). Finding Cronobacter in opened PIF containers does not prove that the PIF was intrinsically contaminated, as opposed to being contaminated after the container was opened; aside from the 2001 outbreak in a Tennessee hospital, FDA did not identify contaminated PIF from lot-matched sealed containers during this time period. Still, Cronobacter contamination during manufacturing remains a possibility; heterogeneous contamination might not be detected through even the most sensitive sampling schemes conducted by FDA and manufacturers (27).

Because PIF remains the most commonly identified transmission vehicle, prevention efforts should focus on minimizing the risk of PIF contamination through regulatory, engineering, and behavioral efforts, and promoting safer alternatives to PIF, particularly among infants $0-2$ months of age. First, sustained focus is needed on identifying and maintaining effective quality control measures during PIF manufacturing. In keeping with regulatory standards, heat-labile nutrients are added to PIF after pasteurization, making it vulnerable to contamination during production, particularly with organisms like Cronobacter, which can persist for long periods in dry environments (28). The implementation of FDA's 2014 quality control standards for safer PIF production was a crucial step toward preventing the distribution of intrinsically contaminated PIF. However, recent outbreaks of infant salmonellosis linked to contaminated PIF produced in Spain in 2010 and France in 2017 highlight the ongoing risk for PIF contamination occurring during production and the value of environmental monitoring for potential contamination $(29,30)$.

Even if contamination does not occur during production, PIF can easily become contaminated once containers are opened and exposed to the environment. Although vigilant adherence to best hand-hygiene practices is necessary when preparing, handling, and storing PIF, engineering solutions, which remain a cornerstone of public health 
preventive efforts, are also needed. Redesigning PIF packaging with the aim of minimizing environmental exposure and contact with contaminated surfaces could help prevent transmission of Cronobacter and other pathogens (31).

Healthcare providers, lactation consultants, and nutritionists play vital roles in supporting and educating caregivers about the risks of PIF contamination (32). They can help communicate that PIF is not a sterile product, while providing education and support for caregivers who choose to use PIF. The 2007 WHO recommendations to reconstitute PIF with water heated to $\geq 70^{\circ} \mathrm{C}$ should reduce pathogen load in reconstituted PIF, but these recommendations have not been universally adopted because of concerns about the potential effect on heat-sensitive nutritional components (including probiotics), impracticality, and burn risks (12). One report also suggested that the WHO-recommended method might not effectively kill all strains of Cronobacter (33). With these concerns in mind, promotion of safer alternatives to PIF, particularly for infants in the neonatal period, is needed.

Safer alternatives to PIF include direct breastfeeding, feeding with breastmilk that has been expressed safely, and feeding with liquid formula that has been safely handled and stored. Although the number of Cronobacter cases among infants who consumed PIF far outnumbered those among infants who exclusively received breastmilk, emerging reports of cases linked to contaminated EBM raise concern about hygiene practices during expression and handling of breastmilk. Comprehensive support can help caregivers to adhere to best practices. CDC offers guidance for proper breast pump hygiene, advising caregivers to wash hands thoroughly before handling pump equipment and to take apart and clean breast pump kits in the dishwasher or by hand with soap and water with a dedicated basin and brush after every use; air dry them on a clean surface in a protected area; and sanitize them at least daily by boiling, steaming, or using a dishwasher's sanitize cycle.

The associated costs and required system supports should be taken into account when weighing the costs and benefits of PIF and PIF alternatives. RTF formula is more expensive than PIF; 2012 comparisons estimated that milk-based RTF formula cost US \$0.84 (29\%) more per day than milk-based PIF (12). Increased support for parental leave and onsite lactation facilities at places of employment will also make direct breastfeeding and safe breastmilk expression easier during critical exposure periods for Cronobacter and other infant illnesses.
The cases in which no source/vehicle was identified, as well as the cases occurring among infants who did not consume PIF or EBM, suggest that alternate modes of transmission are possible. Vertical transmission, although theoretically possible, is probably rare; only 4 patients experienced symptom onset in the first 48 hours after birth. C. malonaticus has been isolated from a breast abscess, but transmission during direct breastfeeding has never been reported (34). Contaminated environmental specimens suggest that fomite transmission could also occur, although the source of the contamination is unclear. Two cases involving Cronobacter-contaminated water (Table 3) highlight that even bottled and previously boiled water used to reconstitute PIF could become contaminated once opened and exposed to the environment, particularly if it does not contain residual chlorine.

This study has limitations. The changes in surveillance we describe might have affected the trend analyses, and because reporting Cronobacter cases is largely not mandatory, the analysis might have been influenced by a severity bias. Additional limitations include incomplete reporting of clinical characteristics, laboratory confirmation, feeding histories, and long-term outcomes. In some cases, clinical isolates were discarded before a public health laboratory could confirm the diagnosis. Other cases might have been excluded or the clinical syndrome misclassified if cultures were taken after initiation of antimicrobial drug therapy. Limitations of case investigations include that many food and environmental specimens were unavailable at the time of the investigation. Finally, the Cronobacter isolates included in this analysis were compared using PFGE, which might have limited capacity to differentiate between genetically unrelated strains within the same clonal complex. In other investigations, whole-genome sequencing and multilocus sequencing typing have offered more precise determinations of genetic similarity (35).

Considering the potential for severe outcomes and far-reaching policy implications, jurisdictions may consider making invasive Cronobacter infections among infants a reportable condition. Mandatory reporting with standardized reporting procedures would help better characterize incidence, elucidate risk factors, promptly detect outbreaks, and inform prevention measures. We encourage public health officials to contact CDC when investigating invasive Cronobacter cases in infants.

\section{Acknowledgments}

We thank Judith Noble-Wang, Heather Moulton-

Meissner, Molly Freeman, Michelle Gleason, Elisa Elliot, and Susan Lance. 


\section{About the Author}

Dr. Strysko is an Epidemic Intelligence Service officer in the Waterborne Disease Prevention Branch, Division of Foodborne, Waterborne, and Environmental Diseases, National Center for Emerging and Zoonotic Infectious Diseases, CDC, Atlanta, Georgia, USA. His primary research interests are neonatal infections and waterborne diseases.

\section{References}

1. Bowen $A B$, Braden $C R$. Invasive Enterobacter sakazakii disease in infants. Emerg Infect Dis. 2006;12:1185-9. https:/ / doi.org/ 10.3201/eid1208.051509

2. Urmenyi AM, Franklin AW. Neonatal death from pigmented coliform infection. Lancet. 1961;1:313-5. https:/ / doi.org/10.1016/S0140-6736(61)91481-7

3. Muytjens HL, Zanen HC, Sonderkamp HJ, Kollée LA, Wachsmuth IK, Farmer JJ III. Analysis of eight cases of neonatal meningitis and sepsis due to Enterobacter sakazakii. J Clin Microbiol. 1983;18:115-20. https:/ / doi.org/10.1128/ JCM.18.1.115-120.1983

4. van Acker J, de Smet F, Muyldermans G, Bougatef A, Naessens A, Lauwers S. Outbreak of necrotizing enterocolitis associated with Enterobacter sakazakii in powdered milk formula. J Clin Microbiol. 2001;39:293-7. https://doi.org/10.1128/JCM.39.1.293-297.2001)

5. Patrick ME, Mahon BE, Greene SA, Rounds J, Cronquist A, Wymore K, et al. Incidence of Cronobacter spp. infections, United States, 2003-2009. Emerg Infect Dis. 2014;20:1520-3. https://doi.org/10.3201/eid2009.140545

6. Food and Agriculture Organization of the United Nations, World Health Organization. Enterobacter sakazakii (Cronobacter spp.) in powdered follow-up formulae: meeting report. 2008 [cited 2019 Feb 14]. https:/ / www.who.int/ foodsafety/publications/micro/MRA_followup.pdf

7. Forsythe SJ. Updates on the Cronobacter genus. Annu Rev Food Sci Technol. 2018;9:23-44. https://doi.org/10.1146/ annurev-food-030117-012246

8. Simmons BP, Gelfand MS, Haas M, Metts L, Ferguson J. Enterobacter sakazakii infections in neonates associated with intrinsic contamination of a powdered infant formula. Infect Control Hosp Epidemiol. 1989;10:398-401. https:// doi.org/10.2307/30144207

9. Biering G, Karlsson S, Clark NC, Jónsdóttir KE, Lúdvígsson $P$, Steingrímsson $\mathrm{O}$. Three cases of neonatal meningitis caused by Enterobacter sakazakii in powdered milk. J Clin Microbiol. 1989;27:2054-6. https:/ / doi.org/10.1128/ JCM.27.9.2054-2056.1989

10. Noriega FR, Kotloff KL, Martin MA, Schwalbe RS. Nosocomial bacteremia caused by Enterobacter sakazakiki and Leuconostoc mesenteroides resulting from extrinsic contamination of infant formula. Pediatr Infect Dis J. 1990;9:447-9. https:// doi.org/10.1097/00006454199006000-00018

11. Centers for Disease Control and Prevention. Enterobacter sakazakii infections associated with the use of powdered infant formula - Tennessee, 2001. JAMA. 2002;287:2204-5.

12. Jason J. Prevention of invasive Cronobacter infections in young infants fed powdered infant formulas. Pediatrics. 2012;130:e1076-84. https:/ / doi.org/10.1542/peds.2011-3855

13. United States Food and Drug Administration Enforcement Story Archives. Center for Food Safety and Applied Nutrition. 2002 [cited 2019 Feb 14]. https:/ / www.fda.gov/ iceci/enforcementactions/enforcementstory/ enforcementstoryarchive/ucm105959.htm

14. Food and Agriculture Organization of the United Nations, World Health Organization. Safe preparation, storage and handling of powdered infant formula: guidelines. 2007 [cited 2019 Feb 14]. http:/ / www.who.int/foodsafety/ publications/micro/PIF_Bottle_en.pdf

15. United States Food and Drug Administration. FDA takes final step on infant formula protections. 2014 Jun 9 [cited 2019 Feb 14]. https:/ / www.fda.gov/ForConsumers / ConsumerUpdates/ucm048694.htm

16. Bowen A, Wiesenfeld HC, Kloesz JL, Pasculle AW, Nowalk AJ, Brink L, et al. Notes from the field: Cronobacter sakazakii infection associated with feeding extrinsically contaminated expressed human milk to a premature infant-Pennsylvania, 2016. MMWR Morb Mortal Wkly Rep. 2017;66:761-2. https://doi.org/10.15585/mmwr.mm6628a5

17. McMullan R, Menon V, Beukers AG, Jensen SO, van Hal SJ, Davis R. Cronobacter sakazakii infection from expressed breast milk, Australia. Emerg Infect Dis. 2018;24:393-4. https://doi.org/10.3201/eid2402.171411

18. Sundararajan M, Enane LA, Kidwell LA, Gentry R, Danao S, Bhumbra S, et al. Notes from the field: Cronobacter sakazakii meningitis in a full-term neonate fed exclusively with breast milk - Indiana, 2018. MMWR Morb Mortal Wkly Rep. 2018;67:1248-9. https:// doi.org/10.15585/ mmwr.mm6744a7

19. PubMLST: public databases for molecular typing and microbial genome diversity [cited 2019 Feb 14]. https://pubmlst.org

20. Chaves CEV, Brandão MLL, Lacerda MLGG, Rocha CABC, Leone de Oliveira SMDV, Parpinelli TC, et al. Fatal Cronobacter sakazakii sequence type 494 meningitis in a newborn, Brazil. Emerg Infect Dis. 2018;24:1948-50. https://doi.org/10.3201/eid2410.180373

21. Muytjens HL, Zanen HC, Sonderkamp HJ, Kollée LA, Wachsmuth IK, Farmer JJ III. Analysis of eight cases of neonatal meningitis and sepsis due to Enterobacter sakazakii. J Clin Microbiol. 1983;18:115-20. https:/ / doi.org/10.1128/ JCM.18.1.115-120.1983

22. Block C, Peleg O, Minster N, Bar-Oz B, Simhon A, Arad I, et al. Cluster of neonatal infections in Jerusalem due to unusual biochemical variant of Enterobacter sakazakii. Eur J Clin Microbiol Infect Dis. 2002;21:613-6. https://doi.org/10.1007/s10096-002-0774-5

23. Teramoto S, Tanabe $Y$, Okano E, Nagashima T, Kobayashi M, Etoh Y. A first fatal neonatal case of Enterobacter sakazakii infection in Japan. Pediatr Int. 2010; 52:312-3. https:// doi.org/10.1111/j.1442-200X.2010.03030.x

24. Drudy D, Mullane NR, Quinn T, Wall PG, Fanning S. Enterobacter sakazakii: an emerging pathogen in powdered infant formula. Clin Infect Dis. 2006;42:996-1002. https://doi.org/10.1086/501019

25. Coignard B, Vaillant V, Vincent JP, Lefleche A, Mariani-Kurkdjian P, Bernet C, et al.. Severe infections of Enterobacter sakazakii in neonates who consumed powdered infant formula, France, October-December 2004 [in French]. Bulletin Epidemiologique Hebdomadaire. 2006;2-3:10-3.

26. Farmer JJ III. My 40-year history with Cronobacter/ Enterobacter sakazakii-lessons learned, myths debunked, and recommendations. Front Pediatr. 2015;3:84. https://doi.org/10.3389/fped.2015.00084

27. Jongenburger I, Reij MW, Boer EP, Gorris LG, Zwietering MH. Actual distribution of Cronobacter spp. in industrial batches of powdered infant formula and consequences for performance of sampling strategies. Int J Food 
Microbiol. 2011;151:62-9. https:// doi.org/10.1016/ j.ijfoodmicro.2011.08.003

28. Jaradat ZW, Al Mousa W, Elbetieha A, Al Nabulsi A, Tall BD. Cronobacter spp. - opportunistic food-borne pathogens. A review of their virulence and environmentaladaptive traits. J Med Microbiol. 2014;63:1023-37. https://doi.org/10.1099/jmm.0.073742-0

29. Jones G, Pardos de la Gandara M, Herrera-Leon L, Herrera-Leon S, Varela Martinez C, Hureaux-Roy R, et al. Outbreak of Salmonella enterica serotype Poona in infants linked to persistent Salmonella contamination in an infant formula manufacturing facility, France, August 2018 to February 2019. Euro Surveill. 2019;24.

https://doi.org/10.2807/1560-7917.ES.2019.24.13.1900161

30. Rodriguez-Urrego J, Herrera-Leon S, Echeita-Sarriondia A, Soler P, Simon F, Mateo S; Investigation team. Nationwide outbreak of Salmonella serotype Kedougou associated with infant formula, Spain, 2008. Euro Surveill. 2010;15:19582.

31. Earnest GS, Reed LD, Conover D, Estill C, Gjessing C, Gressel M, et al.; Centers for Disease Control and Prevention. Engineering and public health at CDC. MMWR Suppl. 2006;55:10-3.

32. Appleton J, Laws R, Russell CG, Fowler C, Campbell KJ, Denney-Wilson E. Infant formula feeding practices and the role of advice and support: an exploratory qualitative study. BMC Pediatr. 2018;18:12. https://doi.org/10.1186/ s12887-017-0977-7
33. Losio MN, Pavoni E, Finazzi G, Agostoni C, Daminelli P, Dalzini E, et al. Preparation of powdered infant formula: could product's safety be improved? J Pediatr Gastroenterol Nutr. 2018;67:543-6. https:/ / doi.org/10.1097/ MPG.0000000000002100

34. Iversen C, Mullane N, McCardell B, Tall BD, Lehner A, Fanning S, et al. Cronobacter gen. nov., a new genus to accommodate the biogroups of Enterobacter sakazakii, and proposal of Cronobacter sakazakii gen. nov., comb. nov., Cronobacter malonaticus sp. nov., Cronobacter turicensis sp. nov., Cronobacter muytjensii sp. nov., Cronobacter dublinensis sp. nov., Cronobacter genomospecies 1 , and of three subspecies, Cronobacter dublinensis subsp. dublinensis subsp. nov., Cronobacter dublinensis subsp. lausannensis subsp. nov. and Cronobacter dublinensis subsp. lactaridi subsp. nov. Int J Syst Evol Microbiol. 2008;58:1442-7. https:/ / doi.org/ 10.1099/ijs.0.65577-0

35. Alsonosi A, Hariri S, Kajsík M, Oriešková M, Hanulík V, Röderová $\mathrm{M}$, et al. The speciation and genotyping of Cronobacter isolates from hospitalised patients. Eur J Clin Microbiol Infect Dis. 2015;34:1979-88. https://doi.org/ $10.1007 /$ s10096-015-2440-8

Address for correspondence: Jennifer R. Cope, Centers for Disease Control and Prevention, 1600 Clifton Rd NE, Mailstop C09, Atlanta, GA 30329-4027, USA; email: cronobacter@cdc.gov
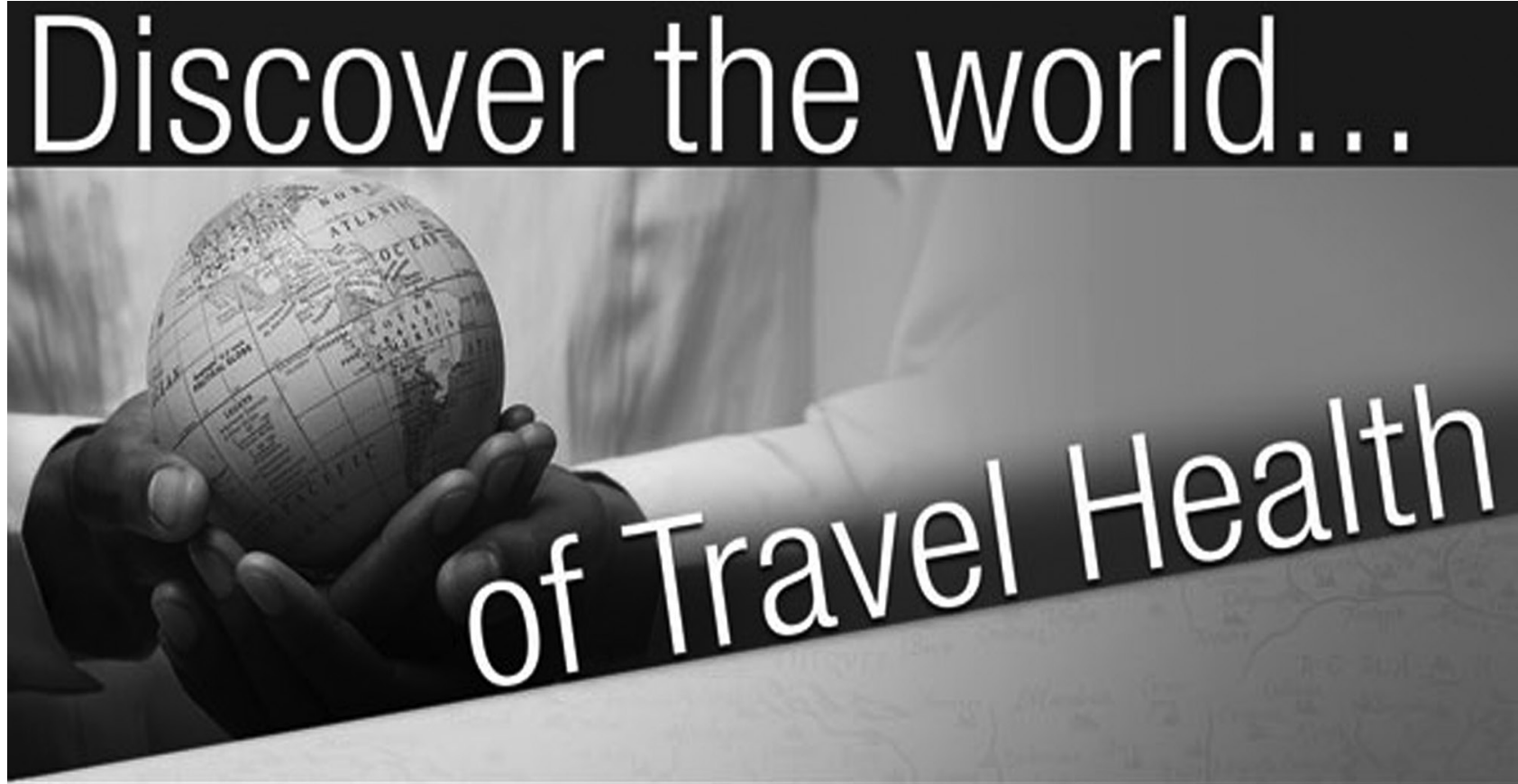

WwW.cdc.gov/travel

Visit the CDC Travelers' Health website for up-to-date information on global disease activity and international travel health recommendations.

Department of Health and Human Services - Centers for Disease Control and Prevention 